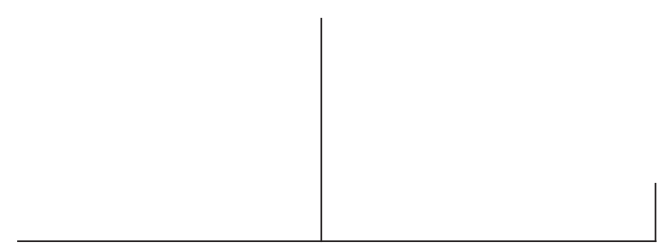

Rev. Latinoam. Psicop. Fund., II, 3, 75-88

\title{
Sujeito, desamparo e violência
}

\author{
Isabel da Silva Kahn Marin
}

\begin{abstract}
A proposta deste trabalho é refletir sobre a violência na sociedade contemporânea, entendendo-a como uma forma possível do sujeito dar conta da situação de desamparo provocada por exigências pulsionais crescentes o que o expõe, portanto, a um excesso de excitação.

Para compor este trabalho, a autora partiu da hipótese de que a tentativa de cada sujeito humano em negar uma violência primordial é o que o leva a sentir dificuldade de se colocar como referência diante do outro que dele depende. Esta falta de referência acarreta para o sujeito grande desamparo frente às suas necessidades pulsionais. Discute-se, a partir daí, que um indivíduo submetido a forças pulsionais intensas pode ser capaz de atos violentos destrutivos como afirmação última de singularidade.

O trabalho retoma, de um lado, a partir da ótica freudiana, a concepção do EU como uma forma de defesa dos ataques provenientes seja das pulsões internas, seja do exterior.
\end{abstract}

* Texto apresentado no III Congresso de Psicopatologia Fundamental, no painel "Violência, dor e desamparo", São Paulo, abril de 1998. 


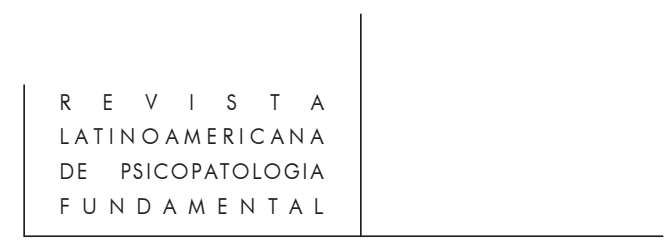

$O$ ato de violência se instaura quando o adulto atende o frágil ser desamparado que é um bebê recém-nascido, desiludindo-o da sensação nirvânica. Desenvolve-se assim a idéia da violência articulada à constituição do sujeito, inspirada também nos trabalhos de Piera Aulagnier e Conrad Stein. De outro lado, procura-se discutir, a partir da contribuição de Calligaris, algumas características da sociedade contemporânea e do imaginário pós-moderno, que contribuem para que as exigências pulsionais a que são submetidos os indivíduos sejam cada vez maiores. Nessa sociedade narcisista, o ideal de autonomia predomina e o individualismo é a meta. Assim sendo, a idéia de submeter o outro à própria vontade parece ser uma violência inominável. Interpretar a necessidade desse outro, buscar as possíveis formas de satisfazê-la, ir ao encontro das leis de regulação social, implicam em enunciar a falta, em relembrar a catástrofe da perda da estabilidade, do Nirvana. É assumir a violência fundamental que permite a relação com o outro, de forma criativa $e$ não fusionada, como muitas vezes se faz em nome da felicidade e do amor. Essa é a condição do aparecimento do sujeito.

Palavras-chave: Sujeito, violência, desamparo, pulsão. 


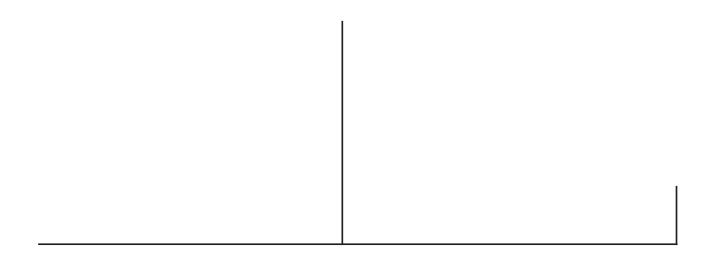

Pesquisar e pensar sobre a questão da violência, sintoma social tão marcante em nossos tempos, tem sido meu desafio atual. Esta tarefa de analisar manifestações sociais, políticas e culturais pela psicanálise foi inaugurada por Freud e muitas contribuições nesse sentido vêm sendo desenvolvidas. Não podemos silenciar frente a esses fenômenos, e a teoria psicanalítica também nos ensina como “a palavra recalcada está intimamente vinculada à violência e à dor. Não se fala o que dói e a violência silencia" (Berlinck e Rodriguez, 1987: 10). Tenho pensado esse fenômeno articulando-o à questão da subjetividade. Parece-me que a tentativa de negação de se assumir a violência fundamental, que é condição para a subjetividade, pode estar contribuindo na formação de práticas aniquiladoras, como afirmação última de singularidade. Essa tendência se relaciona, provavelmente, ao imaginário social pós-moderno, onde prevalecem os valores individuais condicionados à realização pessoal.

Pretendo, no presente trabalho, discutir como essas questões estão intrinsecamente relacionadas com a questão do desamparo, situação emocional muito significativa no homem contemporâneo.

Precisar a noção de desamparo que aqui utilizarei se faz então necessário. Vou me basear, no presente trabalho, nas concepções freudianas sobre a situação de desamparo. Essa se estabelece quando toda possibilidade de simbolização está abolida e o sujeito se vê à mercê de suas forças pulsionais, estando ele, portanto, exposto a um excesso de excitação. Entendo esse momento como um sentimento de abandono diante do desejo desconhecido do outro. Penso também que na sociedade contemporânea, onde o ideal de autonomia predomina, essa questão fica mais evidenciada, já que o individualismo é a meta, e que submeter ao outro a própria vontade, parece ser uma violência inominável. "Respeitar o outro" - abandoná-lo às suas fantasias - não se instalaria aí um grande desamparo? 


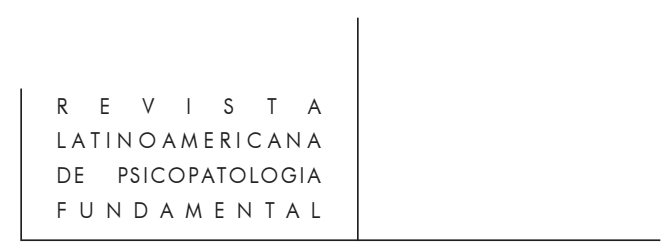

A questão da subjetividade vem sendo objeto de minhas preocupações desde o início de minha carreira profissional. O que garante a formação da subjetividade, que condições sociais devem se estabelecer para garantir esse processo, que formas de subjetivação podem ser pensadas para além do modelo familiar, foram as questões que nortearam minha dissertação de mestrado ${ }^{1}$.

Pensar como uma criança precocemente abandonada poderia se subjetivar era muito desafiador, e questões importantes em relação ao desamparo já aí se delineavam. Discutia que o problema dessas crianças não era a perda da família, a falta e a separação, mais sim a impossibilidade de significar essa situação. Justamente quando se impede que essas crianças falem de sua história e expressem a sua dor, é que se cria a situação de desamparo.

Se eu já discutia, nessa época, que um dos aspectos comprometedores do processo de identificação das crianças institucionalizadas era a ausência da Função Paterna, com o que eu chamava de "predominância da ideologia do amor", essa característica foi se tornando muito marcante nas mais diferentes instituições educacionais com as quais eu continuo em contato - desde os berçários de classe média, passando pelas creches, até as instituições para crianças e adolescentes em situação de risco social.

A dificuldade de assumir o lugar da lei, de se colocar no lugar de quem frustra, permitir que a criança entre em contato com sua história dolorosa para que possa fazer seu luto simbólico e se organizar, entre muitas outras situações que eu poderia enumerar, vão se constituindo em dificuldades quase insuperáveis no trabalho educacional. "Como não ser violento com meu filho para conseguir que ele durma, pois ele faz cenas terríveis e não quero magoá-lo?", perguntou-me um pai na oportunidade de uma palestra de orientação cujo tema era 'dilemas na educação de filhos"2.

Diferentes situações que venho testemunhando, como essas que acabo de citar, levam-me a constatar que o lugar da lei, da referência e da ordem tem sido preterido a pretexto do prazer, do amor, da felicidade, da criatividade. Em nome da autonomia, os educadores frente às crianças, os pais frente aos filhos e até mesmo o homem frente à mulher (e vice-versa), não assumem que devem propor, exigir ou reivindicar. Cada um pressupõe o que é melhor para si. Se o ideal do homem moderno é a autonomia, parece que estamos muito próximos dessa meta. Como observa Calligaris

1. "O lugar do Outro, ou A conquista da identidade num espaço institucional para menores carentes", que foi publicada sob o título FEBEM, Família e Identidade. São Paulo, Babel Cultural, 1988. $2^{\underline{a}}$ edição revisada, São Paulo, Escuta, 1999.

2. A criança em questão tem um ano e meio de idade, não consegue adormecer, faz escândalos até de madrugada, a ponto da vizinhança queixar-se. 


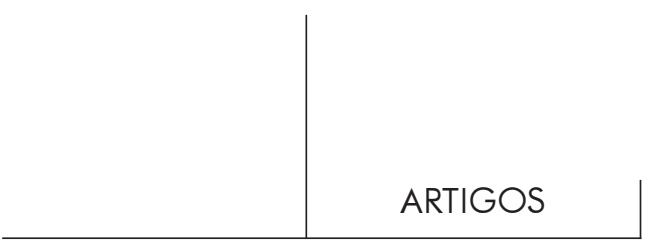

(1996 - I) “em nossa época, diluem-se os valores e as referências tradicionais e, talvez momentaneamente, prevaleça a caça às imagens agradáveis".

A sociedade contemporânea, onde impera o narcisismo, está então regulada por critérios estéticos, muito mais do que por critérios éticos. Calligaris aponta que para o homem pós-moderno, importa apenas sua satisfação pessoal que será garantida se conseguir assumir a imagem divulgada pela mídia como ideal. Para tal, basta possuir os objetos que o tornam próximo ao ideal social proposto. Para possuir esses objetos não vale a lei da conquista, do esforço, do espírito comunitário, da construção de um projeto comum. Ao jovem, vale tudo para conseguir o que quer. Portanto, é possível entendermos o porquê ser tão difícil para o adulto ocupar o lugar da lei, da referência, do que frustra ou contraria, como sinalizei anteriormente. $\mathrm{O}$ adulto une-se à mídia e promete ao jovem o acesso ao consumo de objetos de desejo, mostrando-se muito mais como sedutor do que como representante de autoridade.

Como pensar, então, no drama da subjetivação? Será, provavelmente, uma catástrofe subjetiva ver-se privado do objeto de desejo, ou melhor, do fetiche, do talismã que dá poder para se colocar e se sustentar no discurso coletivo (Jerusalinsky, 1994). Até matar vale, se é para possuir o necessário, abater o objeto da frustração, impor o Eu. "Privados do objeto do qual precisávamos para ser alguém, arriscamos a não ser mais ninguém. Isto basta para sair atirando" (Calligaris, 1996: 31). Aqui chegamos à violência enquanto emprego desejado da agressividade, com fins destrutivos; uma experiência de excesso que visa o aniquilamento do outro, ataque ao sujeito, ataque ao social. Não se trata mais da violência primária ou fundamental.

É indiscutível que a questão da violência tem sido objeto de preocupação generalizada em nossa sociedade, e a mídia aponta para o índice crescente do nível de violência.

Teremos, a partir do quadro exposto acima, uma explicação para esse fenômeno?

Fica assim estabelecido um enigma que é o que me proponho a discutir. Como é que, quando o que mais assusta o homem é o ter que assumir ser violento tendo que reprimir e frustrar, assumindo o lugar da lei e da ordem (lembremo-nos do pai citado anteriormente) - maiores têm sido as manifestações de violência em nossa sociedade? O que parece mover a todos é apenas a busca de prazer, passandose ao ato na busca da realização de qualquer desejo. $\mathrm{O}$ que penso é que quanto mais se procura negar a violência - a presença do outro na relação com cada um, ousando assumir e determinar o lugar que esse um ocupa frente ao desejo daquele outro - mais se abandonam os sujeitos aos seus próprios impulsos, à ilusão de ser onipotente. Certamente a reação onipotente é uma resposta possível frente a situação de desamparo à qual é submetido o homem contemporâneo. Para esse indivíduo, a 


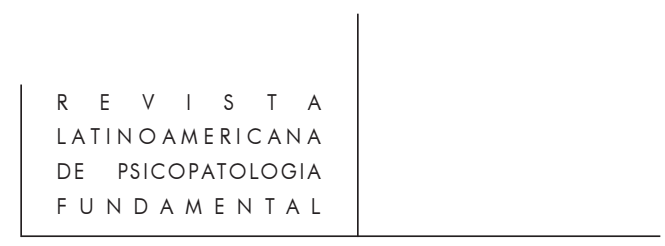

idéia de submissão ao outro é insuportável. Rompem-se laços sociais. Estar só acaba por tornar-se o modelo ideal da maturidade.

Mas voltemos à discussão sobre a violência fundamental e a dificuldade de assumi-la.

Desde Freud, a psicanálise aponta, por outro lado, que a violência é, enquanto fundadora da civilização, determinante da subjetividade. O homem da cultura é herdeiro e cúmplice de um crime, fato que tenderá a ser negado e perpetuado por toda a humanidade. As vicissitudes do complexo edípico retomam, na constituição da subjetividade de cada um, toda essa contradição. Amor à mãe, ódio ao pai, que é obstáculo a esse amor, supressão do desejo de assassinar o pai por temor à castração, submissão ao outro para preservar subjetividade - nesse paradigma clássico da psicanálise, já temos os elementos que levam a pensar na questão da violência como elemento fundante da subjetividade. Sabe-se, também, que muito antes de configurar-se dessa forma - amor à mãe, ódio ao pai - o infans é violentado pelo discurso da mãe que lhe marcará a existência do mundo em confronto com sua psique: reconhecer um espaço separado do próprio.

Psique e mundo se encontram e nascem um com o outro, um para o outro; são o resultado de um estado de encontro que dissemos ser co-extensivo ao estado de existente. A inevitável violência imposta pelo discurso teórico ao objeto psíquico decorre de sua necessidade de dissociar os efeitos desse encontro. (Aulagnier, 1975: 33).

Manoel Berlinck também tem discutido como o processo de subjetivação se dá em função de uma insuficiência imunológica psíquica, ou seja, no "fracasso" que o aparelho psíquico tem em enfrentar os ataques contínuos que se fazem a um estado primeiro de equilíbrio, "ao sentimento oceânico, sentimento primário cujo conteúdo ideacional a ele apropriado seria exatamente o de ilimitabilidade e o de um vínculo com o universo" (Freud, 1930: 77).

Desde a ótica freudiana, portanto, o Eu aparece como uma forma de se defender, de dar conta desses ataques provenientes quer seja das pulsões internas, quer seja do exterior, desse adulto que ao atender esse frágil ser desamparado que é o bebê humano recém-nascido, o violenta ao lhe dar aquilo mesmo que ele precisa.

Chamaremos de violência primária à ação psíquica pela qual se impõe à psique de um outro uma escolha, um pensamento ou ação, motivado pelo desejo daquele que o impõe, mas que são, entretanto, apoiados num objeto que para o outro corresponde à categoria do necessário. (Aulagnier, 1975: 38)

É interessante ressaltar alguns pontos que Freud retoma em Mal-estar na civilização, onde claramente descreve a confusão que é para o bebê distinguir as fontes de excitação originárias de seus próprios órgãos corporais, daquelas 


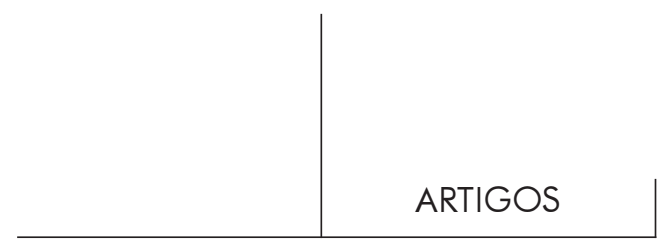

provenientes dos cuidados de sua mãe e principalmente das sensações que lhe provocam o seu distanciamento (da mãe). A noção de exterioridade começará a ser esboçada aí: no reconhecimento das excitações e na vivência da aproximação/ distância, representada pelo seio materno, que é necessária para o alívio desse desequilíbrio. E na mesma medida em que esse outro exterior (mãe) é fonte de satisfação de necessidades, ele é ameaça, já que quebra o sentimento de unicidade.

Outro incentivo para o desengajamento do ego com relação à massa geral de sensações, isto é, reconhecimento de um exterior, é proporcionado pelas freqüentes, múltiplas e inevitáveis sensações de sofrimento e desprazer, cujo afastamento e cuja fuga são impostos pelo princípio do prazer. Surge então uma tendência a isolar do ego tudo que pode tornar-se fonte de tal desprazer, e lançá-lo para fora e a viver um puro ego em busca do prazer, que sofre o confronto de um "exterior" estranho e ameaçador. (p. 76)

Faço essas citações que, na verdade, enunciam os fatos já tão conhecidos hoje em psicanálise, mas que lançam as bases para a discussão sobre o que, de fato, constitui a subjetividade. O Eu, portanto, é uma construção necessária para dar conta de administrar todas as tensões sofridas pela força das diversas exigências internas e externas. Freud também vai discutir como o Ego se estrutura a partir das relações objetais vividas, ou seja, é um bricolage de identificações, tentando evitar a ansiedade, isto é, a "perturbação econômica provocada pelo acúmulo de quantidade de estímulos que precisam ser eliminados" (Freud, 1926: 136). Isto, no fundo, é uma forma de lidar com o medo provocado pela ausência da figura protetora e de amor (a mãe, por exemplo), garantia de aplacamento da tensão. É criada uma organização para enfrentar o desamparo. Desde "Sobre o narcisismo: uma introdução", Freud vai trabalhar essas idéias, o recriar dentro do Ego uma relação que repete a relação ideal mãe/bebê e os ideais parentais.

Como ficaria esse processo então quando o ideal parental é o da felicidade, da imagem ideal de um bebê sem angústias que os reafirmem enquanto bons pais? Será provavelmente insuportável sentirem-se porta-vozes do mundo externo que frustra, ao lembrarem que o paraíso não existe. Ao trazerem a ruptura, interpretando necessidades, acabam por determinar no seu bebê a ansiedade, condição da formação do psiquismo. Mas se é insuportável assumir o lugar do "mau”, do feio, é possível que esse pais se calem, abandonando o bebê a seus próprios fantasmas. Pensemos no pai que não queria frustrar seu filho e colocá-lo para dormir. A excitação dessa criança incontrolada pedia uma intervenção que, em último caso, acabaria sendo feita pela polícia chamada pelos vizinhos.

Finalmente, quando Freud desenvolve, a partir de "Além do princípio do prazer", a idéia da Pulsão de Morte, que junto a Eros funciona como mola propulsora do aparelho psíquico, dizendo que "ambos os instintos seriam conservadores no 


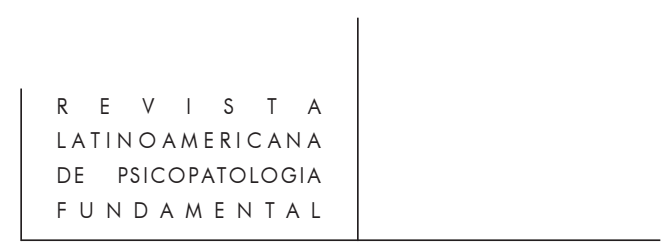

sentido mais estrito da palavra, visto que ambos estariam se esforçando para restabelecer um estado de coisas que foi perturbado pelo surgimento da vida" (Freud, 1923: 53), temos todos os conceitos que contribuem para a análise que venho desenvolvendo. A necessidade do outro como provedor frente ao desamparo provocado pela natureza - Eros combinando indivíduos isolados, famílias, raças etc. - a civilização necessária. O desequilíbrio provocado pela "voz" do outro que atende e, portanto, aponta para a fragilidade e que ao marcar uma exterioridade, quebra o sentimento oceânico, mobilizando Pulsão de Morte que quer silêncio, que se manifesta na destrutividade, quebrando vínculos.

Eis a dinâmica da luta da espécie humana pela vida, e é aí que cada sujeito humano se constitui.

Essas reuniões de homens devem estar libidinalmente ligadas umas às outras. A necessidade, as vantagens do trabalho em comum, por si sós, não as manterão reunidas. Mas o natural instinto agressivo do homem, a hostilidade de cada um contra todos e a de todos contra cada um, se opõe a esse programa de civilização. Este instinto agressivo é o derivado e o principal representante do Instinto de Morte que descobrimos lado a lado de Eros e com esse divide o domínio do mundo. E é essa batalha de gigantes que nossas babás tentam apaziguar com sua cantiga de ninar sobre o céu. (Freud, 1930: 126)

O mais interessante, como sabemos, é que Freud irá discutir e descobrir como a civilização vai se organizar para inibir a agressividade que se lhe opõe. Mais uma vez, veremos, com o conceito de Super Ego, como o Eu se organiza e se modifica para, atendendo aos princípios da civilização - nova violência - apaziguar os impulsos dos seus aspectos primitivos - o Id, unindo-se ao seu princípio, ou seja, o do prazer, à redução de tensão. "A civilização, portanto, consegue dominar o perigoso desejo de agressão do indivíduo, enfraquecendo-o, desarmando-o e estabelecendo no seu exterior um agente para cuidar dele como uma guarnição numa cidade conquistada". (p.127)

Vemos, assim, como cada sujeito se descobre na sua relação com o outro, ao ser enunciado pelos pais, ao ser iludido e frustrado continuamente no desejo de completude e de ser uno (fusão à mãe). O infans descobre que a mãe amada não está à serviço apenas de suas necessidades pulsionais, pois o priva, o violenta, ao interpretar suas faltas, ao enunciar sua carência, ao lembrar sua dissociação com o mundo. Piera Aulagnier designa bem esse processo com seu conceito de violência primária.

Devo mencionar aqui também, o trabalho de Conrad Stein - As Erínias de uma mãe. Ensaio sobre o ódio, onde esse autor vai retomar de forma bastante original a questão da violência fundamental como constituinte mesmo da subjetividade. Analisa o momento fundante do nascimento de um bebê e o corte da 


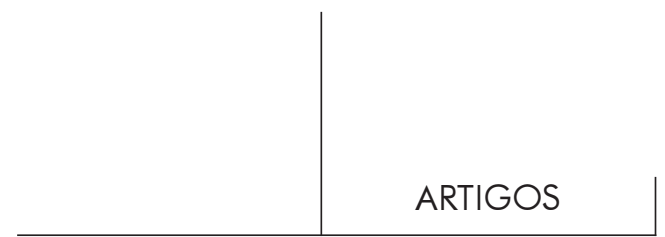

relação mãe/bebê simbolizado pelo umbigo, que leva sempre à questão: esse umbigo é o da mãe ou da criança? O estatuto do sujeito exige que existam dois e esse é o drama. A ilusão não é a da unidade? "O ódio nasce com o objeto, e a 'sombra do objeto caiu sobre o ego', de onde a depreciação de si”. É Freud evocado por Stein. Ele continua: "Desde o dia do meu nascimento, o ódio de minha mãe caiu sobre mim, eu me odeio, ou, em termos mais elegantes, estou sendo perseguido pelas Erínias de uma mãe (Stein, 1988: 47). (...). Em outros termos, o ódio é o resultado da onipotência supostamente perdida, da onipotência inerente a esta infância préhistórica à qual Freud concedeu um lugar central" (p. 63).

Nesse ponto, penso ser importante retomar a articulação da questão do desamparo e da violência na constituição da subjetividade. Vou utilizar para isso as contribuições de Luiz Hanns. É interessante notar que em seu Dicionário comentado do alemão de Freud, não trabalha especificamente o termo Hilflosigkeit, utilizado por Freud para descrever o estado de desamparo. Esse termo aparece em seu glossário alemão-português, mas está remetido ao termo Reiz-excitação, estímulo. $\mathrm{O}$ verbete Reiz, por outro lado, merece uma longa análise. Importante ressaltar que, em sua etimologia, o verbo Reizen "deriva do verbo Reißen, cujo significado original era fazer um risco, arranhão - ranhura. Hoje, Reißen significa rasgar, separar violentamente" (Hanns, 1996, p. 222). Será em seus comentários sobre o termo Reiz que o autor vai dar grande destaque à questão do desamparo.

É antiga a idéia em Freud de que o excesso de Reize é vivido pelo sujeito como algo avassalador que o leva ao estado de desamparo (Hilflosigkeit). Esse termo é carregado de intensidade, e expressa um estado próximo do desespero e do trauma. Esse estado é semelhante àquele vivido pelo bebê, o qual é incapaz, pelas próprias forças, de remover o excesso de excitação pela via de satisfação, sucumbindo à Angst. (Hanns, p. 228)

Penso que, portanto, é inevitável que o adulto (a mãe) suporte essa condição que lhe é paradoxalmente colocada. Ao mesmo tempo que ela é o representante do corte, da arranhadura no sentimento oceânico, associando-se ao sentimento de desamparo provocado no bebê, é ela que pode, ao atender as suas necessidades, interpretando-as, aliviar sua tensão pulsional. Mas com certeza, para realizar isso, o adulto deve ser capaz de tolerar, de ser colocado no lugar do "violento", do representante do ódio (lembremos Stein). Aí, parece que entramos em contradição com o imaginário contemporâneo.

Poder suportar o ataque de raiva que uma criancinha tem ao ser frustrada, em suas buscas de encontrar o seio, por exemplo, ou mesmo quando aparentemente não quer adormecer e demora para se aconchegar; poder niná-la, e não imaginar que ela precisa ainda de mais estímulos e excitação, requer uma grande tranqüilidade no enfrentamento ao ódio. Como nos aponta Calligaris: 


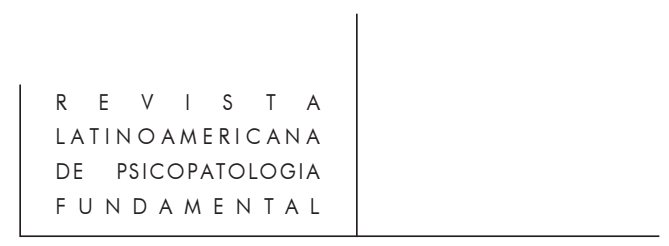

A felicidade que queremos (adultos) contemplar nelas (crianças), é a caricatura de nossos devaneios. As queremos, paradoxalmente, livre de nós, assim como sonhamos ser livres de nossos pais, e possuidores de objetos, pois atribuímos aos objetos o valor de talismã. (...) também não seria de estranhar que as crianças, de repente, possam se tornar tão assassinas e cruéis quanto nós. Pois os "os adultos em miniatura", para serem felizes, devem manter da infância justamente a isenção daqueles estorvos que nos fazem tão pouco amáveis aos nossos próprios olhos; o peso do dever e da dívida com as gerações anteriores, a hesitação do juízo moral, o rigor da lei. Em suma, queremos que sejam anões de férias sem lei. E podem acabar sendo. (Calligaris, 1996 - III, p. 17)

Penso, portanto, que se não formos capazes de assumir nossa própria violência, que é reativada em toda experiência de relação com o outro, ao descobrirmos a distância, a fissura, a Reiz, que paradoxalmente toda relação significativa impõe, abandonaremo-nos, a nós e o outro, ao desamparo. E mais, estaremos muito próximos de nos responsabilizarmos pela violência aniquiladora, no sentido de se ir ao ato para a satisfação das necessidades, através de uma descarga imediata.

"Violência branca" (Marin, 1996), é o que chamei a tendência da instituição para jovens abandonados em se apresentar de uma forma sedutora, onde o jovem pode fazer o que quiser, onde não existem regras claras de convivência, onde ele não é obrigado a participar de nenhuma atividade, onde se fecham os olhos para o consumo e tráfico de drogas etc. Nesse mesmo trabalho discuto como não é dada ao jovem abandonado a oportunidade de se organizar, já que o espaço institucional não se organiza com leis, a partir das quais ele possa se referenciar e denunciar aquilo que lhe falta, ser ouvido e aprender a buscar soluções dentro dos princípios colocados pela ordem social. Penso que justamente na tentativa de se mostrar perfeita, com educadores que não querem ocupar o lugar de "maus", a instituição está justamente tentando negar a sua origem que é a de ser o resíduo da violência que a sociedade procurou excluir: crianças que foram maltratadas por pais que estão sendo violentados cotidianamente pelas condições sócioeconômicas do país. A instituição acaba, dessa forma, produzindo outra violência que é a de abandonar os jovens aos seus próprios impulsos, novo desamparo.

Assim está constituído o paradoxo contemporâneo. O ideal de felicidade concretizado numa sociedade de consumo, onde supostamente a posse de objetos garantiria a imagem idealizada, que é a da plena satisfação, ao mesmo tempo que a demanda de objetos se faz sempre crescente. Podemos pensar que as exigências pulsionais se fazem cada vez maiores. Isso sem falarmos na liberação sexual que essa mesma sociedade promoveu e que também se une a uma suposta possibilidade de satisfação plena (gozo), já que as barreiras da repressão parecem tão diluídas. Por um lado, temos então uma enorme demanda de busca de satisfação, já que os critérios de renúncia pulsional em nome dos valores tradicionais está abolida em 


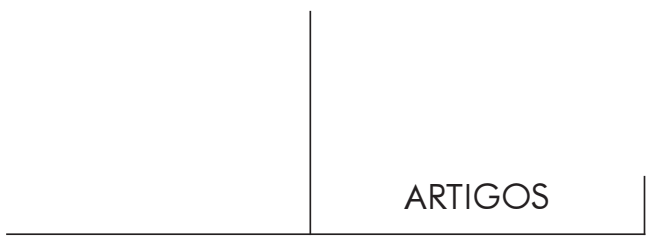

função de imagens prazerosas, como já analisamos. Por outro lado, temos condições sócioeconômicas (que aqui são consideradas, porém não serão objeto de análise) que dificultam, em muito, as possibilidades de realização dessa demanda.

Entre esse dois pólos temos, como procurei analisar no decorrer desse trabalho, sujeitos que têm muita dificuldade em suportar o compromisso frente ao outro que os remeteriam a situação de ruptura, de representantes do ódio/violência.

Interpretar a necessidade do outro, buscar as possíveis formas de satisfazêlas, ir ao encontro das leis de regulação social, já implica em enunciar a falta, em relembrar a catástrofe da perda da estabilidade. É assumir a violência primordial que permite a relação com o outro, de forma criativa e não fusionada, massificada, como muitas vezes em nome do amor e da felicidade se faz. É a condição do aparecimento do sujeito. Pretendi ter demonstrado como, se isso não é feito, se expõe o sujeito a um desamparo insuportável e que aí só lhe resta na busca do alívio da tensão pulsional, destruir o outro, aniquilá-lo - ser violento.

Neste momento, não posso deixar de lembrar Winnicott (1987), que considera, no gesto anti-social, o último grito de esperança para o sujeito que reivindica do Social, aquilo que lhe foi prometido. Não deixa de ser a denúncia de uma impostura. É a busca de um mundo bom que foi perdido, rompido abruptamente. A sociedade contemporânea promete que para ser alguém, é necessário ter sempre mais. Para ser possível tornar-se Homem, é necessário "respeitar e amar o próximo" que acena sempre com mais uma exigência, uma promessa, um produto a ser consumido.

Bibiliografia

Aulagnier, P. A violência da interpretação. Do pictograma ao enunciado. Rio de Janeiro, Imago, 1975.

BERLINCK, M.T. “Introdução à Psicopatologia Fundamental”, apresentado no II Congresso de Psicopatologia Fundamental, São Paulo, abril de 1997.

e Rodriguez, S.A. (orgs.). Psicanálise de sintomas sociais. São Paulo, Escuta, 1988.

Calligaris, C. "Um narcísico mundo novo". Boletim de Novidades da Livraria Pulsional, São Paulo, nº 86, junho de 1996 (I).

"Cena de sangue numa rua do Bronx". Boletim de Novidades Livraria Pulsional, São Paulo, $\mathrm{n}^{\mathrm{o}}$ 86, junho de 1996 (II).

"O reino encantado chega ao fim". Boletim de Novidades da Livraria Pulsional, São Paulo, no ${ }^{\circ}$ 86, junho de 1996 (III).

Freud, S. Obras Completas. Edição Standard Brasileira. Rio de Janeiro, Imago, 1996. "O ego e o id" (1923). ESB, vol. XIX, op. cit., pp. 73-148.

"Inibição, sintoma e ansiedade" (1926). ESB, vol. XX, op. cit., pp. 81-171. 
“O mal-estar na civilização” (1930). ESB, vol. XXI, op. cit., pp. 73-148.

"Novas conferências introdutórias sobre a psicanálise" (1933). ESB, vol. XXII, op. cit., pp. 63-112.

"Esboço de psicanálise" (1940). ESB, vol. XXIII, op. cit., pp. 153-221.

Hanns, L. Dicionário comentado do Alemão de Freud. Rio de Janeiro, Imago, 1996.

Jerusalinsky, A. e Tavares, E. "Era uma vez... já não é mais". Folha de S. Paulo, Caderno "Mais!", 24.07.1994.

MARIN, I. Kahn. "Instituição e violência, violência nas instituições". Texto apresentado no II Encontro Adolescência e Violência-Conseqüências da Realidade Brasileira, FAU/USP, São Paulo, 12.10.96.

Stein, C. As Erínias de uma mãe. Ensaio sobre o ódio. São Paulo, Escuta, 1988.

Winnicotr, D.W. Privação e delinqüência. São Paulo, Martins Fontes, 1987.

\section{Bibliografia complementar}

Aulagnier, P. Os destinos do prazer. Rio de Janeiro, Imago, 1985.

Freud, S. "Três ensaios sobre a teoria da sexualidade" ( 1905). ESB., vol. VII. Rio de Janeiro, Imago, 1996. "Totem e tabu" (1913). ESB, vol. XIII, op. cit. "Sobre o narcisismo: uma introdução" (1914). ESB, vol. XIV, op. cit. - "Os instintos e suas vicissitudes" (1915). ESB, vol. XIV, op. cit. "Luto e melancolia" ( 1917). ESB, vol. XIV, op. cit. "Reflexões para tempos de guerra e morte" (1915). ESB, vol. XIV, op. cit. "Além do princípio do prazer" (1920). ESB, vol. XVIII, op. cit. "Psicologia de grupo e análise do ego" (1921). ESB, vol. XVIII, op. cit. "O futuro de uma ilusão" (1927). ESB, vol. XXI, op. cit.

LACAN, J. O Seminário. Livro 2 - O Eu na teoria de Freud e na técnica de psicanálise. Rio de Janeiro, Zahar, 1985. La familia. Argentina, Homo Sapiens, 1977.

Pereira, M.E. Costa. "O pânico e os 'fins da análise"”. Percurso - Revista de psicanálise, pp. 29-37, São Paulo, $1^{\circ}$ Semestre de 1997.

"A questão psicopatológica do pânico examinada à luz da noção metapsicológica de desamparo". Boletim de Novidades da Livraria Pulsional, São Paulo, $\mathrm{n}^{\mathrm{o}}$ 84, abril de 1996.

\section{Resumos}

Este trabajo se propone a hacer una reflexión sobre la violencia en la sociedad contemporánea, entendiendo por violencia una manera posible por la cual el sujeto enfrenta la situación de desamparo provocada por exigencias pulsionales crecientes lo que lo expone, por tanto, a un exceso de excitación. 


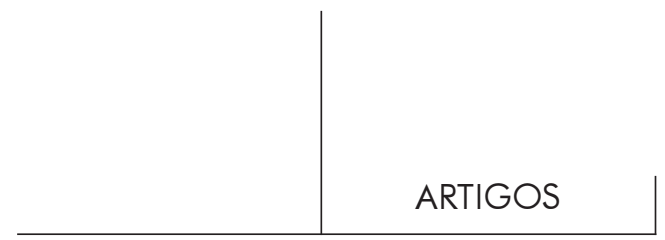

Para elaborar este trabajo, la autora partió de la hipótesis de que la tentativa de cada sujeto humano en negar una violencia primordial es lo que lo lleva a sentir dificultades para posesionarse como referencia frente al otro que depende de él. Esta falta de referencia acarreta para el sujeto un gran desamparo frente a sus necesidades pulsionales. A partir de este punto se discute que un individuo submetido a intensas fuerzas pulsionales puede ser capaz de actos violentos destructivos como una afirmación última de singularidad.

Este trabajo retoma, de un lado, a partir de la óptica freudiana, la concepción del Yo como una forma de defensa de los ataques provenientes sea de las pulsiones internas, sea del exterior. El acto de violencia se instaura cuando el adulto atiende al ser frágil y desamparado que es un nene recién nacido, desilusionandolo de la sensación nirvánica. De este modo se desarrolla la idea de violencia articulada a la constitución del sujeto, inspirada también en los trabajos de Piera Aulagnier y Conrad Stein. Por otro lado se trata de discutir, a partir de la contribución de Calligaris, algunas características de la sociedad contemporánea y del imaginario pós moderno; las cuales contribuyen para que las exigencias pulsionales a las que son submetidos los individuos se hagan cada vez mayores. En esa sociedad narcisista, el ideal de autonomía predomina y el individualismo es la meta. Siendo así, la idea de submeter al otro a su propia voluntad parece ser una violencia innominable. Interpretar la necesidad de ese otro, buscar las formas posibles de satisfacerla, ir de encuentro a las leyes de regulación social, implican en enunciar la falta, en recordar la catástrofe de la pérdida de la estabilidad, del Nirvana. Es asumir la violencia fundamental que permite la relación con el otro, de forma creativa y no fusionada, como muchas veces se hace en nombre de la felicidad y del amor. Esta es la condición de emergencia del sujeto.

Palabras llave: Sujeto, violencia, desamparo, pulsiones.

Ce travail se propose à réfléchir sur la violence dans la société contemporaine, en la comprenant comme une forme possible par laquelle le sujet rend compte de la situation d'abandon provoquée par des exigences pulsionnelles croissantes, ce qui l'expose donc à un excès d'excitation.

Pour composer ce travail, l'auteur est partie de l'hypothèse selon laquelle la tentative primordiale de chaque sujet à nier une violence primordiale c'est ce qui le conduit à sentir une difficulté à se poser comme référence devant l'autre qui dépend de lui. Cette manque de référence entraîne pour le sujet un grand abandon face à ses besoins pulsionnels. On discute à partir de lá qu'un individu soumis à des forces pulsionnelles intenses peut être capable des actes violents et destructifs comme affirmation ultime de singularité.

Le travail reprend, d'un coté, à partir de l'optique freudienne, la conception $d u$ Moi comme une forme de défense aux attaques provenantes soit des pulsions internes, soit de l'extérieur. L'acte de violence s'instaure quand l'adulte répond au être fragile et abandonné qui est un bébé nouveau-né, en le désenchantant de la sensation nirvanique. 


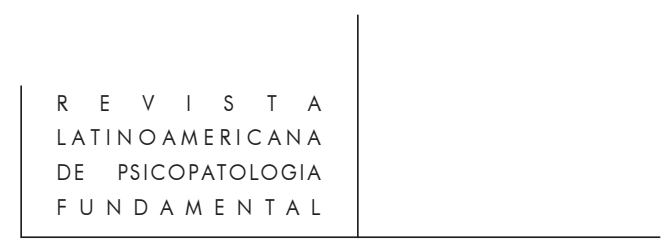

L'idée de violence articulée à la constitution du sujet se développe ainsi inspirée aussi des travaux de Piera Aulagnier et Conrad Stein. De l'autre coté, on cherche à discuter, à partir de la contribution de Calligaris, quelques caractéristiques de la société contemporaine et de l'imaginaire postmoderne, qui contribuent pour que les exigences pulsionnelles auxquels les individus sont soumis soient des plus en plus augmentées. Dans cette société narcissiste, l'idéal de l'autonomie prévalait, et l'individualisme c'est le but. Ainsi, l'idée de soumettre l'autre à sa propre volonté y parâ̂t une violence innommable. Interpréter le besoin de cet autre, rechercher les formes possibles de le satisfaire, affronter les lois de régulation sociale, tout cela implique une énonciation de la faute, un rappel de la catastrophe de la perte de la stabilité, du Nirvana. C'est d'assumer la violence fondamentale qui permet la rélation avec l'autre, d'une forme créatrice et pas fusionné, comme on fait tant de fois au nom de la félicité et de l'amour. Ceci est la condition de l'apparition du sujet.

Mots clés: Sujet, violence, abandon, pulsion. 